\title{
A pesquisa como princípio educativo no Ensino Médio Integrado à Educação Profissional: uma experiência pedagógica no IFSul
}

\author{
Research as an educational principle in High School Integrated \\ with Professional Education: a pedagogical experience at IFSul
}

\author{
Maria Raquel Caetano (caetanoraque2013@gmailcom) \\ Instituto Federal Sul-rio-grandense (IFSul)
}

Marineiva Teresinha de Melo Manganeli (marineivamanganeli@ sapucaia.ifsul.edu.br) Instituto Federal Sul-rio-grandense (IFSul)

\begin{abstract}
Resumo: O artigo apresenta o resultado de uma pesquisa-ação cujo tema foi o desenvolvimento de uma prática utilizando a pesquisa como como princípio pedagógico na Educação Profissional e Tecnológica, realizada com estudantes e professores de uma turma de primeiro ano do Curso Técnico Integrado em Mecânica no IFSul-Campus Sapucaia do Sul/RS no ano de 2019. Essa pesquisa buscou produzir melhorias qualitativas no processo de ensino e aprendizagem através do uso da pesquisa. Partiu-se de uma ação intencional para desenvolver o eixo formativo do curso na proposta do Ensino Médio Integrado à Educação Profissional. Ao longo do processo essa prática foi sendo construída especialmente pelos estudantes com a mediação dos professores, a partir da metodologia da problematização. Percebemos que a concepção da pesquisa como princípio educativo e pedagógico buscou articular a construção do conhecimento ao projeto pedagógico do curso e a uma concepção de educação integrada. Buscamos, com essa experiência inicial, a formação dos estudantes numa perspectiva integral e integrada.
\end{abstract}

Palavras-chave: Ensino Médio; Pesquisa; Problematização

\begin{abstract}
The article presents the result of an action research whose theme was the development of a practice using research as a pedagogical principle in Professional and Technological Education, carried out with students and teachers of a first year class of the Integrated Technical Course in Mechanics at IFSul-Campus Sapucaia do Sul / RS in 2019. This research sought to produce qualitative improvements in the teaching and learning process through the use of research. It was based on an intentional action to develop the formative axis of the course in the proposal of High School Integrated to Professional Education. Throughout the process, this practice was built especially by students with the mediation of teachers, based on the methodology of problematization. We realized that the concept of research as an educational and pedagogical principle sought to articulate the construction of knowledge with the pedagogical project of the course and with a concept of integrated education. With this initial experience, we seek to train students in an integral and integrated perspective.
\end{abstract}

Keywords: High School; Search; Questioning.

Recebido em: $01 / 09 / 2020$

Aceito em: $27 / 10 / 2020$ 


\section{INTRODUÇÃO}

A pesquisa contribui para a construção da autonomia intelectual do educando que, nos Institutos Federais, deve ser intrínseca ao ensino, bem como estar orientada ao estudo e busca de soluções para a vida do estudante, sendo síntese da articulação com as diferentes áreas do conhecimento. Como princípio educativo, a pesquisa é uma ação do pensamento inserida na totalidade social cuja construção do sentido é emancipatória. Nessa perspectiva, a pesquisa, como princípio pedagógico, compreende os processos de ensinar e aprender e a investigação como prática de criação e de desejo de conhecer, realizando descobertas e, acima de tudo, podendo ser democrática, diversa e plural.

Educar pela pesquisa é um princípio pedagógico que se insere na Educação Profissional, haja vista que nas Diretrizes Curriculares Nacionais da Educação Básica (BRASIL, 2013), na seção que aborda a Educação Profissional Técnica de Nível Médio, traz que "[...] é necessário que a pesquisa como princípio pedagógico esteja presente em toda a educação escolar dos que vivem/viverão do próprio trabalho" (BRASIL, 2013, p. 218). A educação pela pesquisa pode ser um meio de promover, no sujeito, aprendizagens que possibilitem o "desenvolvimento da autonomia intelectual, da consciência crítica envolvendo também a capacidade de questionamento e de intervenção crítica na sua realidade" (DEMO, 2003, p. 86).

O objetivo foi desenvolver com os estudantes e professores um processo que apresentou como eixo central a pesquisa enquanto princípio educativo, formativo e pedagógico, buscando o fortalecimento das relações entre ensino e pesquisa sob as dimensões do trabalho, da ciência e da cultura. Para tal proposta, organizamos o artigo em três seções: 1) Ensino médio integrado, formação integral e integrada, em que apresentamos o contexto e importância do Ensino Médio Integrado a Educação Profissional; 2) O ensino médio integrado e a pesquisa como princípio pedagógico, em problematizamos currículo integrado e a pesquisa como uma das alternativas de integração e de formação de um sujeito integral, autônomo e crítico; 3) Proposta Metodológica em que apresentamos os caminhos escolhidos para desenvolver a pesquisa a partir da metodologia da problematização que auxilia nas etapas da pesquisa-ação e descrevemos a prática desenvolvida com algumas análise e por fim as Considerações Finais em que apresentamos resultados obtidos ao longo do processo. 


\title{
1)ENSINO MÉDIO INTEGRADO, FORMAÇÃO INTEGRAL E INTEGRADA
}

O Decreto $\mathrm{n}^{\mathrm{o}}$ 5.154, de 23 de julho de 2004, retomou a perspectiva da articulação/integração entre a Educação Básica e a Educação Profissional, por meio do Ensino Médio Integrado que reestabeleceu o lugar da educação profissional integrada ao ensino médio. No documento, consta, no Artigo $4^{\circ}$, que a educação profissional técnica de nível médio será desenvolvida de forma articulada com o ensino médio incluindo o $\S$ $1^{\circ}$ que diz:

\begin{abstract}
A articulação entre a educação profissional técnica de nível médio e o ensino médio dar-se-á de forma: I - integrada, oferecida somente a quem já tenha concluído o ensino fundamental, sendo o curso planejado de modo a conduzir o aluno à habilitação profissional técnica de nível médio, na mesma instituição de ensino, contando com matrícula única para cada aluno. (BRASIL, 2004).
\end{abstract}

A Lei 11.892/2008, que instituiu os Institutos Federais de Educação, Ciência e Tecnologia no Artigo $7^{\circ}$, aborda que um dos seus objetivos é ministrar educação profissional técnica de nível médio, prioritariamente na forma de cursos integrados, para os concluintes do ensino fundamental e para o público da educação de jovens e adultos. O Ensino Médio Integrado (EMI) deve se configurar “[...] como um tipo de ensino médio que garanta a integralidade da educação básica, ou seja, que contemple o aprofundamento dos conhecimentos científicos produzidos e acumulados historicamente pela sociedade, como também objetivos adicionais de formação profissional numa perspectiva da integração dessas dimensões" (BRASIL, 2007, p. 24).

No âmbito do Curso Técnico Integrado em Mecânica no Instituto Federal de Educação, Ciência e Tecnologia Sul-rio-grandense, Campus Sapucaia do Sul, onde se desenvolveu a pesquisa, o objetivo geral do curso é formar Técnicos em Mecânica, por meio de uma formação humanística, científica e tecnológica, capacitando-os para sua inserção no mundo do trabalho. Tudo isso se dá de modo compromissado com o desenvolvimento regional e nacional, exercendo atividades de forma crítica, ética e criativa, ou seja, um técnico com formação integral.

Consta no Projeto Pedagógico do Curso (PPC) que a metodologia do trabalho será diversificada, variando de acordo com as necessidades educacionais dos estudantes, o perfil das turmas e as especificidades das disciplinas. Diz o PPC que, a cada ano de 
curso, a metodologia priorizará o diálogo com diversos campos do trabalho, da ciência, da tecnologia e da cultura.

Ao longo do curso serão desenvolvidos projetos integradores envolvendo todas as disciplinas ministradas, buscando temas a serem explorados com o suporte das 18 competências e saberes desenvolvidos em busca da superação do histórico conflito existente em torno do papel da escola de formar para a cidadania ou para o trabalho produtivo, do dilema do conflito do currículo voltado para as humanidades ou para a ciência e tecnologia. (RAMOS, M, 2005, PPC, p.12).

É importante destacarmos que umas das formas de construir sentido para o ensino médio é buscar a integração com a educação profissional técnica de nível médio e o projeto integrador ora proposto. O objetivo é articular as diferentes disciplinas em prol de propostas comuns, contextualizando as aprendizagens dos estudantes. "Nesse horizonte de atuação, ensinar, pesquisar e socializar conhecimentos são práticas interligadas e complementares" (PPC do Curso). Ao longo do trabalho desenvolvido, procuramos atender os objetivos propostos no projeto do curso e a própria concepção de Ensino Médio Integrado, uma proposta central dos Institutos Federais.

\section{2) O ENSINO MÉdIO INTEGRAdO E A PESQUISA COMO PRINCÍPIO}

\section{PEDAGÓGICO}

O Ensino Médio Integrado (EMI) pressupõe que a educação geral se torne inseparável da educação profissional e que a relação entre conhecimentos gerais e conhecimentos específicos seja construída sob as dimensões do trabalho, da ciência e da cultura. Essa proposta visa ao desenvolvimento de todas as potencialidades humanas, na perspectiva de uma formação integral ou omnilateral (RAMOS, 2007).

A dualidade educacional histórica, resultante da divisão social do trabalho, consolidou a separação entre a educação geral, destinada à preparação para o acesso a níveis superiores de ensino, e a educação específica, de caráter técnico profissional. Consolidou-se, assim, uma formação diversa atribuindo a uns a formação para o trabalho intelectual e a outros a formação para o trabalho manual, exclusivamente, com foco no atendimento às demandas do mercado de trabalho.

Para a concretização do EMI, é pressuposto básico a efetivação de práticas em uma perspectiva de superação do atual modelo vigente linear e hierárquico, ou seja, um EMI que abarque as relações entre trabalho e educação, a educação profissional e as 
relações com a educação básica. A pesquisa, como princípio pedagógico, é uma alternativa para a construção de um currículo integrado, que desenvolve atitude científica, buscando soluções e propondo alternativas.

As Diretrizes Curriculares Nacionais para a Educação Básica contribuem para essa compreensão, pois

\begin{abstract}
definida como uma atividade escolar, orientada e motivada pelos professores, [...] implica na identificação de uma dúvida ou problema, na seleção de informações de fontes confiáveis, na interpretação e elaboração dessas informações e na organização e relato sobre o conhecimento adquirido. [...] a prática de pesquisa propicia o desenvolvimento da atitude científica, o que significa contribuir, entre outros aspectos, para o desenvolvimento de condições de, ao longo da vida, interpretar, analisar, criticar, refletir, rejeitar ideias fechadas, aprender, buscar soluções e propor alternativas, potencializadas pela investigação e pela responsabilidade ética assumida diante das questões políticas, sociais, culturais e econômicas. (BRASIL, 2013, p. 218).
\end{abstract}

$\mathrm{Na}$ busca por conhecimentos, que podem ser do senso comum, escolar ou científico, utilizando como aporte teórico-metodológico a pesquisa, como princípio pedagógico, viabilizam-se propostas e respostas de alternativas para problemas da realidade do estudante, do seu ambiente de trabalho (VALER et al., 2017), da escola e para a vida. É com essa possibilidade de integrar formação geral e formação técnica, em atividades que envolvem a pesquisa através de projetos articulados, que se busca enfrentar a divisão entre formação para o trabalho manual e o trabalho intelectual. $O$ EMI tem a possibilidade de concretização de um projeto educacional que visa à melhoria da escolarização para a classe trabalhadora, na perspectiva das concepções de educação politécnica e formação omnilateral.

A formação humana integral ou omnilateral é entendida como um desenvolvimento total do ser humano em todas as dimensões, ou seja, da sua integralidade física, mental, cultural, política e científico-tecnológica. Nessa experiência formativa, serão reveladas as potencialidades que cada sujeito possui (RAMOS, 2007). Nesse sentido, faz-se necessária que a formação profissional esteja articulada com a formação básica, a fim de que o estudante possa se apropriar dos conhecimentos e inserir-se, dignamente, na vida produtiva e na sociedade. Em vista disso:

A possibilidade de integrar formação geral e formação técnica no ensino médio, visando a uma formação integral do ser humano é, por essas determinações concretas, condição necessária para a travessia em direção ao ensino técnico politécnico e à superação da dualidade educacional pela 
superação da dualidade de classes. (FRIGOTTO; CIAVATTA; RAMOS, 2012, p. 45).

Avançar na proposição do Ensino Médio Integrado à Educação Profissional é tarefa prioritária nos Institutos Federais. Isso porque o EMI "representa um processo educativo mediador das relações entre trabalho e educação, numa perspectiva comprometida com a formação da classe trabalhadora" (SCHEIBE; SILVA, 2013, p. 34). Para as autoras, para avançar na construção desse projeto, é necessária “[...] a mobilização dos educadores na construção de um projeto pedagógico que exige a compreensão de novos conceitos que dão sustentabilidade à proposta do EMIEP [...]" (SCHEIBE; SILVA, 2013, p. 35).

Pelo fato de o trabalho definir a existência histórica dos homens, Saviani (1989) destaca que toda a educação organizada se dá a partir do entendimento e da realidade do trabalho, pois a essência do homem é o trabalho, ou seja, o ato de agir sobre a natureza e transformá-la em função das suas necessidades, criando, assim, a cultura, a ciência e a tecnologia. Em relação à organização do Ensino Médio, Saviani (2007) defende a formação pelo domínio das diferentes técnicas utilizadas na produção moderna, no sentido de articular o trabalho manual e o trabalho intelectual. Assim, recupera-se a relação entre o conhecimento e a prática do trabalho, de modo que oriente os estudantes à realização de múltiplas escolhas.

Moura (2007) apresenta alguns eixos norteadores da integração entre Ensino Médio e Educação Profissional, na qual destacamos: a pesquisa como princípio educativo: como forma de possibilitar a construção da autonomia intelectual e de soluções para as questões do cotidiano do educando, visando ao desenvolvimento de tecnologias para o bem coletivo; a realidade concreta como uma totalidade, síntese de múltiplas relações: a possibilidade, através do currículo integrado, de compreender o contexto no qual o educando está inserido, de forma que possa interferir em função dos interesses coletivos; a interdisciplinaridade, a contextualização e a flexibilidade.

Defendemos as argumentações de Moura e Saviani sobre a integração do EM e EPT uma vez que a educação deve ser, obrigatoriamente, emancipatória. Ela deve proporcionar aos jovens estudantes uma leitura ampliada do mundo e uma preparação intelectual e profissional para atuar e obter seus meios de vida como forma de lutar pelos seus direitos. 
Ramos (2007) afirma a necessidade de uma organização curricular que atenda à proposta de integração fundamentada por dois pressupostos filosóficos: a concepção de homem como ser histórico-social e a realidade concreta como uma totalidade, síntese de múltiplas relações. A concepção de integração que o currículo deve assumir implica a superação da hierarquia existente entre as disciplinas e a classificação como de formação geral e de formação específica e da justaposição entre conhecimentos básicos e aplicados.

Dessa forma, destacamos a importância de compreender o currículo integrado na perspectiva da totalidade ao afirmar que

[...] a integração de conhecimentos no currículo depende de uma postura nossa, cada qual de seu lugar; o professor de Química, de Matemática, de História, de Língua Portuguesa etc podem tentar pensar em sua atuação não somente como professores da formação geral, mas também da formação profissional, desde que se conceba o processo de produção das respectivas áreas profissionais na perspectiva da totalidade. (RAMOS, 2007, p. 19).

Nesse sentido, ao afirmar que o processo de ensino e aprendizagem é um processo complexo e global, Machado (2010) pontua que, para a construção de um currículo integrado, há necessidade da mudança de postura pedagógica, no sentido de romper com a fragmentação dos conteúdos e com a hierarquização de conhecimentos. Para a operacionalização do currículo integrado, são necessárias práticas pedagógicas que priorizem o trabalho coletivo e rompam com o isolamento, em especial, entre os professores da área propedêutica e da área técnica, para que possam planejar as ações educativas conjuntamente. Isso porque é por meio do "planejamento coletivo, consciente, crítico e intencional que as dúvidas, tensões e dificuldades vão sendo superadas construindo relações de totalidade e vão se fortalecendo para avançar na efetivação do currículo integrado" (SILVA, 2014, p. 25).

O desenvolvimento de práticas pedagógicas integradas não configura uma tarefa fácil, porque é uma proposta contra hegemônica, que se direciona contrária aos interesses das reformas em curso que dificultam a sua consolidação. Dentre os desafios, destacamos que as propostas de educar pela pesquisa se opõe a um tipo de educação bancária (FREIRE, 2002), padronizada, baseada na memorização e na reprodução, base da atual reforma educacional, voltada mais para resultados das avaliações em detrimento ao próprio processo de construção pedagógica coletiva, via questionamento, diálogo e participação. 


\section{3)PROPOSTA METODOLÓGICA}

Ao propor o trabalho com pesquisa no primeiro ano do Curso Técnico em Mecânica do Campus Sapucaia do Sul, tivemos como objetivo materializar o eixo formativo: "O mundo do trabalho e a Mecânica". Também era intenção levar a efeito um dos objetivos dos Institutos Federais, de integrar ensino e pesquisa; conhecimento técnico e propedêutico, colaborando para auxiliar na autonomia de aprender dos estudantes, quais sejam: interpretar, analisar, criticar, refletir, buscar soluções e propor alternativas através da investigação e, especialmente, do trabalho colaborativo com os pares. Por isso, a escolha metodológica foi a pesquisa-ação que

pode ser concebida como um procedimento de natureza exploratória, como objetivos a serem determinados pelos pesquisadores conjuntamente com os interessados. Os resultados da exploração são úteis para elucidar a ação e para desencadear outras pesquisas. (THIOLLENT, 1999, p. 99).

Um dos objetivos foi trabalhar a construção dessa experiência com estudantes e professores através do eixo formativo "O mundo do trabalho e a Mecânica", desencadeando o trabalho com a pesquisa. O foco desse processo foi a pergunta, a elaboração de argumentos e a defesa desses, promovendo a formação de um estudante pesquisador, crítico, curioso e socialmente comprometido.

Para desenvolver este estudo, baseamo-nos na Metodologia da Problematização (BERBEL, 1995), embora tenhamos criado outras chaves de interpretá-la, recontextualizando-a, mas a considerando como alternativa metodológica transformadora e dialógica, que parte de uma realidade visando transformá-la de alguma forma (BERBEL, 1996). Essa metodologia prevê uma ação na realidade a partir de uma compreensão com base em saberes adquiridos pela investigação e pela reflexão, fundamentados teoricamente, implicando uma consciência política e social (BERBEL,1996).

Assim, a centralidade deste trabalho está na concepção de pesquisa como princípio pedagógico na Educação Profissional e Tecnológica. Para isso, descreveremos o processo, partindo da figura organizada e apresentada a seguir, iniciando pela Observação da Realidade. 


\section{Figura 1 - Ciclo metodológico}

Fonte: Adaptado por Caetano, a partir de Berbel (1996).

A proposta do trabalho partiu de uma visita técnica. A partir dela, foram desenvolvidos projetos coletivos cujos temas foram escolhidos pelos estudantes através do diálogo crítico com estreita relação às diferentes áreas ligadas ao curso e ao interesse dos estudantes.

Nesta primeira etapa de observação da realidade, foi considerada a realidade que destacamos para investigar: uma visita técnica à Fábrica da Tramontina em Bento Gonçalves-RS. A Tramontina é uma das empresas mais importantes do Brasil, possuindo dez unidades fabris descentralizadas, sendo oito no Rio Grande do Sul, uma no Pará e outra em Pernambuco. No conjunto dessas dez fábricas, a empresa produz, atualmente, mais de 18 mil itens destinados aos mais diferentes segmentos. Tem presença forte também no mercado internacional, com 11 unidades internacionais, exportando para mais de 120 países. Localiza-se no Distrito Industrial em Farroupilha RS. Fabrica panelas, talheres e uma linha completa de aço inoxidável, cozinhas profissionais e eletroportáteis. A unidade visitada foi fundada em 1971, possuindo uma área de $104.680 \mathrm{~m}^{2}$ e 698 funcionários.

Antes do contato com a realidade, fizemos um levantamento do que os estudantes gostariam de ver na empresa e o que seria importante observarem com o objetivo de construirmos projetos de pesquisa. Por exemplo, poderiam verificar o 
maquinário utilizado para produção, equipamentos de segurança no trabalho, materiais utilizados, trabalhadores portadores de deficiência, cuidado com o ambiente, entre outros. Ao estabelecer o contato, partiram para as observações e registros do máximo de informações acerca do objeto de estudo cujo foco principal foi a mecânica e os aspectos a ela relacionados e outros achados que não haviam sido levantados previamente.

No retorno da visita, fizemos momentos de exploração do que haviam observado e o que havia mais chamado a atenção dos estudantes para que pudessem relacionar os temas observados a diferentes áreas do conhecimento. Dessa realidade observada e dos temas explorados, em grupos ou duplas, os estudantes definiram os temas para suas pesquisas.

Os temas versaram sobre diferentes olhares sobre "O mundo do trabalho e a Mecânica", especialmente tendo como referência a visita técnica, mas ampliando a visão e os diferentes pontos de vista dos estudantes sobre o mundo do trabalho e as questões econômicas, políticas, históricas e sociais. Nesse momento dialógico, foram definidos os seguintes temas:

\begin{tabular}{|l|}
\hline Aplicação de robôs industriais com garras mecânicas \\
\hline Erros que causaram tragédias na indústria \\
\hline Inclusão de pessoas com deficiência na indústria \\
\hline Segurança no Trabalho \\
\hline Indústria 4.0 \\
\hline Mecânica de fluidos \\
\hline Circuitos hidráulicos \\
\hline Revolução Industrial \\
\hline Reciclagem de materiais \\
\hline
\end{tabular}

Ao definirem os temas, foi o momento de problematizar, buscar novos elementos, contribuir e aprofundar o entendimento, para realizar articulações e relações com as diferentes áreas do conhecimento do curso. Problematizar e formular o problema a partir do que foi observado tem relação com o grupo, ao modo como ele olha a realidade, a partir dos conceitos e dos valores que possui (BERBEL, 1995), Recebido em: $01 / 09 / 2020$ 
questionando e confrontando o que foi observado, ampliando, assim, sua visão sobre o tema.

Em reunião com os professores do curso, apresentamos os temas escolhidos pelos grupos e, a partir das suas áreas e aproximações com os temas de pesquisa, cada professor se colocou nos projetos cujas disciplinas teriam mais aproximações, a fim de auxiliarem na problematização e na definição de pontos-chaves, ficando à disposição dos grupos para eventuais consultas. Nessa fase, nem todas as disciplinas e professores tinham afinidades aos temas e a essa forma de desenvolver o trabalho, portanto, nem todos participaram diretamente do projeto. Integraram-se ao projeto as disciplinas de: Espanhol, Física, História, Iniciação Acadêmica, Informática, Mecânica e Português.

Em relação à definição de pontos-chaves e à contribuição dos professores, destacamos que

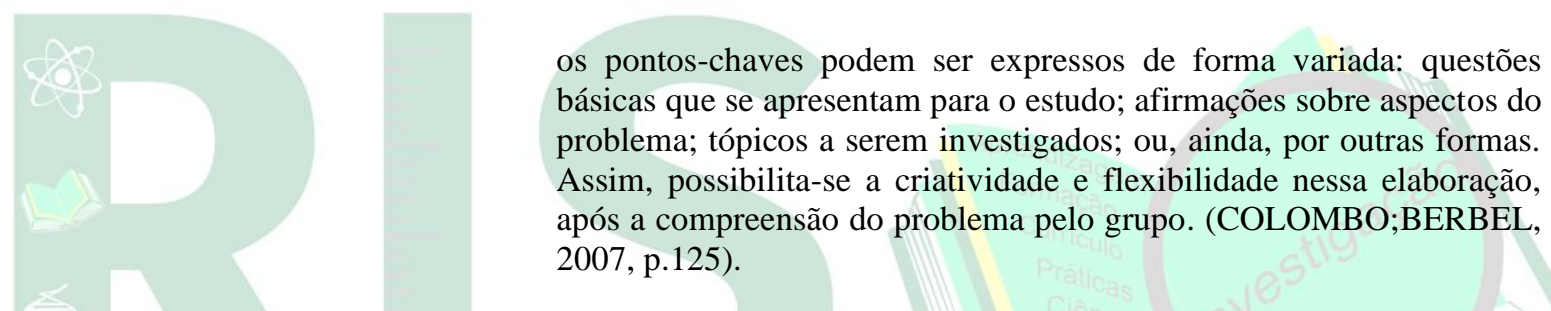

A definição dos pontos-chaves auxilia no aprofundamento dos estudos, e as áreas do conhecimento auxiliam na teorização dos temas de pesquisa. Nesse sentido, todas as áreas fundamentam a pesquisa e auxiliam os estudantes nas relações com os aspectos sócio-históricos, políticos e econômicos a fim de que compreendam o contexto em que estão inseridos bem como o mundo do trabalho atual.

No desenvolvimento desse processo, a disciplina de Iniciação Acadêmica foi responsável pelo desencadeamento dessa proposta e, ao mesmo tempo, desenvolveu o trabalho com a metodologia científica e as etapas de um projeto de pesquisa. Coube a essa disciplina também auxiliar na organização dos projetos, promovendo, com as demais disciplinas e áreas, um trabalho mais integral e integrado. Destacamos aqui a importância do trabalho organizado pelos professores das áreas técnicas e propedêuticas cuja postura pedagógica buscou, nesse exercício conjunto, formas de romper com a fragmentação dos conteúdos e com a hierarquização de conhecimentos. Avaliamos que esta atividade foi um exercício de aproximação e de integração, por isso não tem a pretensão de ser um modelo, mas, sim, uma das muitas formas de romper com processos estandardizados e lineares. 
Conforme Machado (2010), para buscar um currículo integrado, são necessárias práticas pedagógicas que priorizem o trabalho coletivo e rompam com o isolamento buscando planejar conjuntamente, o que foi realizado parcialmente, por ser uma experiência nova em um curso novo. Já a etapa de teorização foi o momento de construir respostas para os problemas definidos pelos grupos. É o momento de aprofundar, levantar dados, registrar, analisar e discutir, buscando dar sentido ao tema e ao problema. A teorização foi desenvolvida com o auxílio dos professores, especialmente no momento de aprofundar temas, definir as formas de realização das pesquisas e as escolhas metodológicas.

As contribuições de Saviani (1984, p.74) indicam que nessa etapa se dá "a apropriação dos instrumentos teóricos e práticos necessários ao equacionamento dos problemas detectados na prática social ou a instrumentalização dos sujeitos" para a resolução dos problemas propostos. Foi o caso de várias disciplinas, como por exemplo: Mecânica e Física ao aprofundar o tema dos robôs e as garras mecânicas, bem como a mecânica de fluidos, em que o professor buscou, além de teorizar, orientar na construção de protótipos com os estudantes. Outro exemplo foi o trabalho desenvolvido na disciplina de Espanhol, quando cada grupo buscou informações sobre os assuntos pesquisados em jornais e revistas de língua espanhola, apresentando, oralmente, em espanhol, o resultado do trabalho e a relação com o tema de estudo.

O papel do professor foi de mediação entre os estudantes e o conhecimento, além de orientador das ações coletivas e individuais. No que pese o trabalho de mediação do professor, destacamos que, nesse processo, foi incentivada a autonomia e a curiosidade dos estudantes em buscar os conhecimentos necessários à resolução dos problemas, ocorrendo de forma surpreendente pela capacidade de ir além do que se propunha inicialmente. A aula se transformou, por muitas vezes, em um espaço coletivo de trabalho, da ação de estudantes e professores em prol da qualidade do conhecimento a ser construído.

A aplicação da realidade é uma etapa destinada à prática dos estudantes na realidade social, ou seja, "o intervir, o exercitar, o manejar situações associadas à solução do problema" (BERBEL, 1995, p.16). Nessa experiência, em particular, consideramos "prática" a ação menos direta, mas intensa de produção dos relatórios de pesquisa e das apresentações produzidas pelos estudantes, pois garantiu, de alguma forma, a aplicação real do estudo em relação ao contexto no qual teve origem o 
problema. Essa etapa, nessa experiência realizada com os estudantes do primeiro ano do Curso Técnico de nível Médio em Mecânica, vários grupos produziram pesquisas aplicadas que geraram modelos/protótipos que foram socializados com o grande grupo. Também consideramos, nessa etapa, a aplicação da metodologia científica que embasou as pesquisas e a construção do relatório orientado pela professora de Português, utilizando os passos de um relatório de pesquisa.

A socialização dos resultados da pesquisa ocorreu através do retorno do estudo realizado ao longo do semestre aos outros sujeitos envolvidos: professores do curso, coordenação e estudantes. Nessa etapa de socialização, combinamos e construímos com o grupo um seminário de apresentação das pesquisas, aberto ao público interno do Campus Sapucaia em que cada grupo compartilhou os resultados das suas produções. Para esse momento, a professora da disciplina de Informática orientou a produção dos slides e todos os recursos que poderiam ser acrescentados como fotos, vídeos e outros. A socialização e a divulgação foi um momento muito esperado, já que foi a oportunidade de mostrar os conhecimentos construídos ao grande grupo e aprender com os demais. Os professores que participaram da experiência estavam presentes e dialogavam com os estudantes ao longo das apresentações.

A avaliação dessa prática realizada ao longo de um semestre foi altamente positiva, embora houvesse sugestões tanto de estudantes quanto de professores de iniciar a atividade no primeiro semestre para dar mais tempo de desenvolver todas as etapas desse processo com mais profundidade. Destacamos que as pesquisas desenvolvidas geraram inquietudes e questionamentos, visando problematizar, para além das temáticas, diferentes visões de mundo, de trabalho e da mecânica.

\section{CONSIDERAÇÕES FINAIS}

Este artigo apresentou o desenvolvimento de uma pesquisa-ação que tinha como objetivo promover a aplicação de uma prática de pesquisa como princípio pedagógico e sua relação com os processos de ensino e aprendizagem na Educação Profissional e Tecnológica. O foco foi o desenvolvimento de uma pesquisa a partir de uma visita técnica que uma turma do primeiro ano do Curso Técnico Integrado em Mecânica realizou, visando articular as disciplinas do curso no Ensino Médio Integrado.

A concepção da pesquisa como princípio educativo e pedagógico buscou articular a construção do conhecimento ao projeto pedagógico do curso e a uma concepção de educação integrada. Buscamos, com essa experiência inicial, a formação 
humana integral entendida como um desenvolvimento total do ser humano em todas as dimensões, ou seja, da sua integralidade: cognitiva, mental, cultural, política e científico-tecnológica. A experiência mostrou o quanto os alunos do primeiro ano, no exercício da sua autonomia intelectual, apresentam condições de interpretar, analisar, criticar, refletir, criar, aprender, buscar soluções e propor alternativas, potencializadas pela investigação e pela responsabilidade que assumem mediante as proposições realizadas pelos professores em ações intencionais e ao mesmo tempo participativa e dialógica com os estudantes.

Concluímos que esse exercício de aproximação das disciplinas, através da pesquisa como princípio pedagógico e educativo, compreendeu a realização de descobertas através de uma prática intencional, sendo construída ao longo do período com os estudantes e professores. Podemos dizer que a pesquisa escolar, voltada para a construção do conhecimento do estudante, com foco na pergunta, na elaboração de argumentos e na defesa desses, auxilia a formar um estudante pesquisador, crítico, curioso e socialmente comprometido. A pesquisa nos Institutos Federais deve ser inerente ao processo pedagógico, buscando a integração dos conhecimentos a partir das sínteses de múltiplas ações e relações da prática educativa.

\section{REFERÊNCIAS}

BERBEL, N. A. N. Metodologia da problematização: uma alterativa metodológica apropriada para o ensino superior. Semina: Ciências Sociais e Humanas, Londrina, v. 16, n. 2, Ed. Especial, p. 9-19, out. 1995.

BERBEL, N. A. N. A metodologia da problematização no ensino superior e sua contribuição para o plano da práxis. Semina: Ciências Sociais e Humanas, Londrina, v. 17, ed. esp., p 7-17, nov. 1996.

BRASIL. Ministério da Educação. Secretaria de Educação Básica. Diretrizes Curriculares Nacionais Gerais da Educação Básica. Diretoria de Currículos e Educação Integral. Brasília: MEC, SEB, DICEI, 2013.

Decreto $\mathbf{n}^{\circ}$ 5.154, de 23 de julho de 2004. Regulamenta o $\S 2^{\circ}$ do art. 36 e os Artigos 39 a 41 da Lei n ${ }^{\circ}$ 9.394, de 20 de dezembro de 1996, que estabelece as diretrizes e bases da educação nacional, e dá outras providências.

Lei $\mathbf{n}^{\mathbf{0}}$ 11.741, de 16 de Julho de 2008a. Altera dispositivos da Lei $\mathrm{n}^{\circ} 9.394$, de 20 de dezembro de 1996, que estabelece as diretrizes e bases da educação nacional, para redimensionar, institucionalizar e integrar as ações da educação profissional técnica de nível médio, da educação de jovens e adultos e da educação profissional e tecnológica. Disponível em: <http://www.planalto.gov.br/ccivil_03/_Ato20072010/2008/Lei/L11741.htm>. Acesso em 10 jul. 2016. 
Lei $\mathbf{n}^{\circ}$ 11.892, de 29 de dezembro de 2008b. Institui a Rede Federal de Educação Profissional, Científica e Tecnológica, cria os Institutos Federais de Educação, Ciência e Tecnologia, e dá outras providências. Disponível em: <http://www.planalto.gov.br/ccivil_03/_Ato2007-2010/2008/Lei/L11892.htm>. Acesso em 10 jul. 2016.

COLOMBO, A. A.; BERBEL, N. A. N. A Metodologia da Problematização com o Arco de Maguerez e sua relação com os saberes de professores. Semina: Ciências Sociais e Humanas, Londrina, v. 28, n. 2, p. 121-146, jul./dez. 2007.

DEMO, Pedro. Pesquisa: princípio científico e educativo. 12. ed. São Paulo: Cortez, 2006.

FREIRE, Paulo. (2002). Pedagogia da autonomia. São Paulo: Paz e Terra.

FRIGOTTO, G.; CiAVATTA, M.; RAMOS, M. (orgs.). Ensino Médio Integrado: concepção e contradições. 3. ed. São Paulo: Cortez, 2012.

MOURA, D. H. Educação básica e educação profissional e tecnológica: dualidade histórica e perspectivas de integração. Holos, Natal, v. 2, p.1-27, 2007.

MACHADO, L. R. de S. Ensino médio e técnico com currículos integrados: propostas de ação didática para uma relação não fantasiosa. In: MOLL, J. e colaboradores. Educação Profissional e Tecnológica no Brasil Contemporâneo: desafios, tensões e possibilidades. Porto Alegre: Artmed, 2010, p. 80-95.

RAMOS, M. Concepção de Ensino Médio Integrado. Seminário sobre ensino médio, realizado pela Superintendência de Ensino Médio da Secretaria de Educação do Estado do Rio Grande do Norte -Natal, 2007.

RAMOS, R. Ensino Médio Integrado: lutas históricas e resistências em tempos de regressão. In: ARAÚJO, A. C.; SILVA, C. N. N. da (orgs.). Ensino Médio Integrado no Brasil: fundamentos, práticas e desafios. Brasília: Ed. IFB, 2017, p. 20-43.

SAVIANI, Dermeval. Escola e Democracia: teorias da educação, curvatura da vara, onze teses sobre educação e política. São Paulo: Cortez, 1984.

SCHEIBE, L.; SILVA, F. L. G. R. da. Ensino Médio à Educação Profissional e sua Potencialidade para a Formação dos Estudantes de Nível Médio: considerações sobre a experiência em Santa Catarina. In: SILVA, M. R. da (org.) Ensino Médio Integrado: travessias. Campinas: Mercado das Letras, 2013, p. 13-38.

SAVIANI, D. Trabalho e educação: fundamentos ontológicos e históricos. Revista Brasileira de Educação, Campinas, v. 12, n. 32, p. 52-180, jan./abr. 2007. Disponível em: http://www.scielo.br/pdf/rbedu/v12n34/a12v1234.pdf. Acesso em: 22 jul. 2020.

SILVA, A. L da. Currículo Integrado. Florianópolis: IFSC, 2014. Disponível em: https://caco.ifsc.edu.br/arquivos/ead/PROEJA_curriculo_integrado.pdf. Acesso em: 10 abr. 2020.

THIOLLENT, Michel. Metodologia da Pesquisa-Ação. São Paulo: Cortez,1999. 
VALER. Salete; BROGNOLI. Ângela; LIMA. Laura. A pesquisa como princípio pedagógico na educação profissional técnica d e nível médio para a constituição do ser social e profissional. Revista Fórum Linguístico. Volume 1 4, Número 4, 2017.

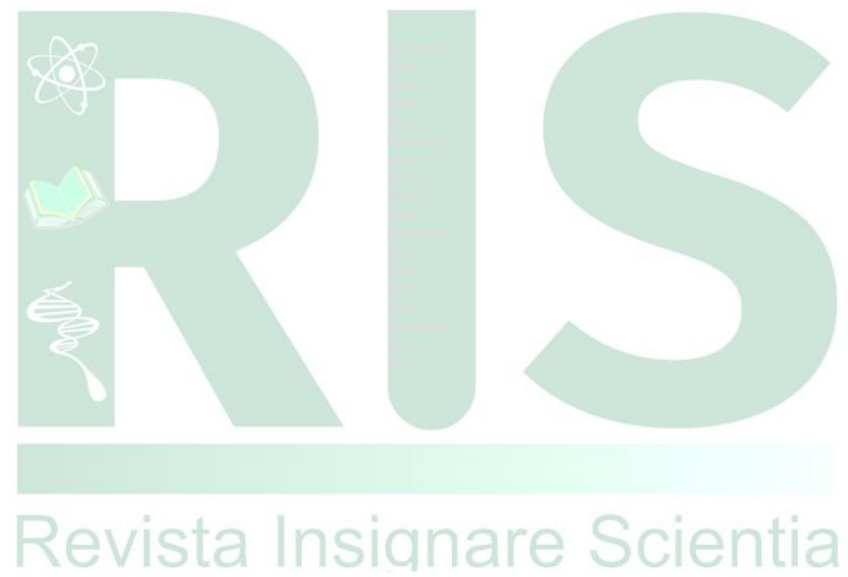

